\title{
Canadian prostate brachytherapy in 2012
}

\author{
Mira Keyes, MD, FRCPC; ${ }^{*}$ Juanita Crook, MD, FRCPC,;s W. James Morris, MD, FRCPC; ${ }^{*}$ Gerard Morton, MD, \\ FRCPC; $;$ Tom Pickles, MD, FRCPC,; Nawaid Usmani, MD, FRCPC Eric Vigneault, MD, FRCPC ${ }^{ \pm}$
}

*Prostate Brachytherapy Program, British Columbia Cancer Agency, Vancouver, BC; Prostate Brachytherapy Program, British Columbia Cancer Agency, Kelowna, BC; §Department of Radiation Oncology, Princes Margaret Hospital, Toronto, ON; *Department of Radiation Oncology, Odette Cancer Center, Toronto, ON; ${ }^{ \pm D e p a r t m e n t ~ o f ~ R a d i a t i o n ~ O n c o l o g y, ~ C r o s s ~ C a n c e r ~ I n s t i t u t e, ~ E d m o n t o n, ~ A B ; ~ £ ~ Q u e b e c ~}$ University Hospital I'Hotel-Dieu de Quebec, Quebec City, QC

Cite as: Can Urol Assoc J 2013;7:51-8. htrp://dx.doi.org/10.5489/cuaj.218

\section{Abstract}

Prostate brachytherapy can be used as a monotherapy for low- and intermediate-risk patients or in combination with external beam radiation therapy (EBRT) as a form of dose escalation for selected intermediate- and high-risk patients. Prostate brachytherapy with either permanent implants (low dose rate [LDR]) or temporary implants (high dose rate [HDR]) is emerging as the most effective radiation treatment for prostate cancer. Several large Canadian brachytherapy programs were established in the mid- to late-1990s. Prostate brachytherapy is offered in British Columbia, Alberta, Manitoba, Ontario, Quebec and New Brunswick. We anticipate the need for brachytherapy services in Canada will significantly increase in the near future. In this review, we summarize brachytherapy programs across Canada, contemporary eligibility criteria for the procedure, toxicity and prostate-specific antigen recurrence free survival (PRFS), as published from Canadian institutions for both LDR and HDR brachytherapy.

\section{Background}

Brachytherapy refers to the placement of radioactive sources directly into cancerous tissue. As radiation dose gradients with brachytherapy are steep, the tumour receives a very high dose of radiation, while the surrounding normal tissues are largely spared - this offers the potential of a high cure rate and minimal toxicity to adjacent organs (Fig. 1a, Fig. 1b). The "modern" era of prostate brachytherapy began in the 1980s with the development of transrectal ultrasound to plan and guide the placement of radioactive sources within the prostate. Based on excellent 15-year prostate-specific antigen (PSA) outcomes, ${ }^{1}$ it has acquired worldwide acceptance. Prostate brachytherapy in Canada began in the mid to late 1990s.

Prostate brachytherapy may be used either as monotherapy for patients with low-risk or low/intermediate-risk disease, or combined with modest doses of external beam, as a method of dose escalation for patients with higher risk disease. ${ }^{2}$ There are 2 forms of prostate brachytherapy: (1) low dose rate (LDR) brachytherapy where radioactive seeds are permanently implanted, or (2) high dose rate (HDR) brachytherapy where treatment is administered over about 10 minutes through temporary catheters that contain the radioactive sources. LDR is most commonly used as monotherapy, whereas HDR is usually used in combination with external beam radiotherapy (EBRT). Both methods are emerging as the most effective radiation treatment for prostate cancer. ${ }^{3}$

Dose escalation using EBRT has been demonstrated to increase long-term PSA outcomes, ${ }^{4-6}$ however the dose of EBRT that can be safely delivered is limited by toxicity from adjacent structures, in particular the rectum. In contrast, brachytherapy is capable of safely delivering much higher doses of radiation than EBRT (Fig. 2). PSA outcomes with brachytherapy in low- and intermediate-risk patients are superior to EBRT, even when delivered using state of the art intensity modulated radiation therapy (IMRT) to 81 Gy. ${ }^{7,8}$ Surveillance, Epidemiology, and End Results (SEER) data on 12745 patients show that at a median follow-up of only 6 years, use of brachytherapy improves prostate cancer cause specific survival in patients with high-risk/high Gleason score (GS) prostate cancer. ${ }^{9}$ The Prostate Cancer Results Study Group (PCRSG) conducted a comprehensive literature review, and identified 18000 studies involving treatment of localized prostate cancer published during 2000 to 2010. Only 848 studies were included in the analysis $(>50000$ patients), based on key criteria: minimum/median follow-up of 5 years; stratification into low-, intermediate- and high-risk groups; clinical and pathological staging; accepted standard definitions for PSA failure; and minimum patient number of 100 in each risk group (50 for high risk). ${ }^{3}$ Patients treated with any form of brachytherapy had not only superior longterm PSA outcome, but also showed remarkable durability of the results with a long follow-up, suggesting 2 important propositions: 
Keyes et al.

1. Unlike EBRT, high radiation dose delivered with brachytherapy produces much lower, usually undetectable PSA levels at long-term follow-up, suggesting an ablative effect of high radiation dose on prostate tissue. ${ }^{10,11}$

2. Most prostate cancer patients, including those with high-risk disease, do not have metastatic prostate cancer at presentation; in fact, eradication of the local disease produces excellent long-term PSA relapse-free outcomes. ${ }^{3,12,13}$

The purpose of this article is to describe prostate brachytherapy practice in Canadian centres, contemporary indications, PSA and toxicity outcomes from Canadian centres. LDR brachytherapy is currently offered in British Columbia, Alberta, Manitoba, Ontario, Quebec and New Brunswick, with over 13000 patients having been implanted so far. HDR brachytherapy is routinely used for intermediate- and high-risk disease in Ontario, Quebec and New Brunswick; recently, it has become part of clinical trials in British Columbia. Over 2000 patients have been treated so far in Canada.

\section{Canadian eligibility criteria}

Patients with low-risk disease $(\leq \mathrm{T} 2, \mathrm{PSA}<10$ and Gleason scores $\leq 6)$ (Canadian Consensus Criteria, which mirror those to the $\mathrm{NCCN})^{14}$ are eligible for LDR brachytherapy as monotherapy in all Canadian provinces with brachytherapy programs. British Columbia, Manitoba, Quebec and Alberta also offer LDR monotherapy to patients with intermediate-risk disease. Ontario currently funds LDR brachytherapy, only for

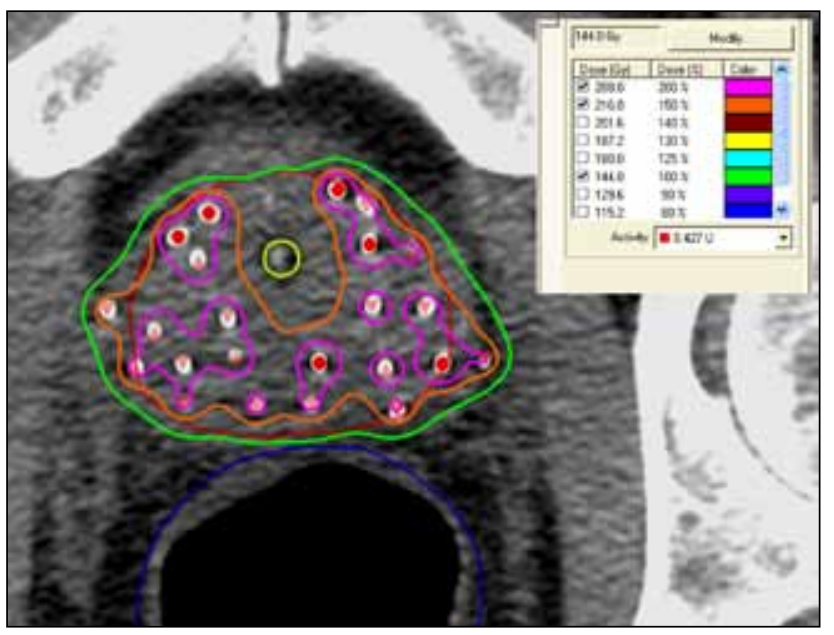

Fig. 1a. Low-dose rate (LDR) dose distribution. Post implant computed tomography scan performed 2 hours after the LDR implant. Prostate is outlined in red, urethra in light green and rectum in blue. Prescription dose of $144 \mathrm{~Gy}$ (green) is covering prostate with several mm margins. 216 $\mathrm{Gy}, 150 \%$ of the prescribed dose (orange) is designed in a "horse-shoe" shape, to avoid urethra. $288 \mathrm{~Gy}, 200 \%$ of the prescribed dose (purple) is concentrated around seeds and at the periphery of the gland. patients with low risk disease. Intermediate $(<\mathrm{T} 2$, PSA $10-20$ or Gleason score $<7$ ) or high risk disease (T3a, PSA $>20$ or Gleason score 8-10) patients are commonly treated with HDR brachytherapy combined with external beam radiotherapy (EBRT).

Active surveillance as a management option has changed the approach to low-risk disease, with fewer patients being offered radical treatments, including LDR brachytherapy. For example, $80 \%$ of the 450 patients in British Columbia who underwent brachytherapy in 2011 had intermediate-risk disease. For those with intermediate-risk cancers, the role of additional therapies is uncertain. Brachytherapy is used to escalate radiation dose within the prostate, while additional EBRT delivers a modest dose of radiation to extraprostatic areas at risk of harbouring microscopic disease. The recently closed Radiation Therapy Oncology Group (RTOG) 0232 randomized clinical trial investigated the role of EBRT in patients with low-tier intermediate-risk disease in addition to brachytherapy (results are pending); while the role of androgen deprivation therapy (ADT) is investigated in the ongoing RTOG 0815 randomized clinical trial. ADT is commonly used in addition to EBRT and brachytherapy (either HDR or LDR) for patients with high-risk disease. Based on a recently completed randomized clinical trial, ASCENDE$\mathrm{RT},{ }^{15}$ British Columbia has revised the treatment options for high-risk disease to include dose escalation with combined LDR and EBRT.

\section{The procedure}

LDR brachytherapy is an hour-long surgical day procedure where radioactive seeds are implanted permanently into the prostate. Patients are discharged 2 to 3 hours later and

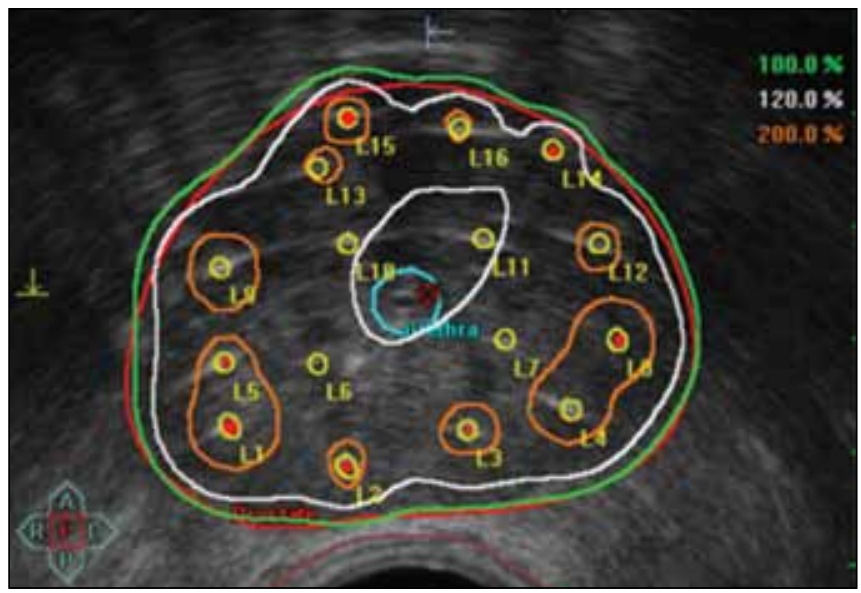

Fig. 1b. High-dose rate dose distribution. Prostate is outlined in red, urethra in light blue and rectum in orange. Prescription dose of $15 \mathrm{~Gy}$ (green) is planned to cover the prostate. $120 \%$ of the prescribed dose (white) is planned to avoid urethra, $200 \%$ of the prescribed dose (orange) is concentrated around catheters. 


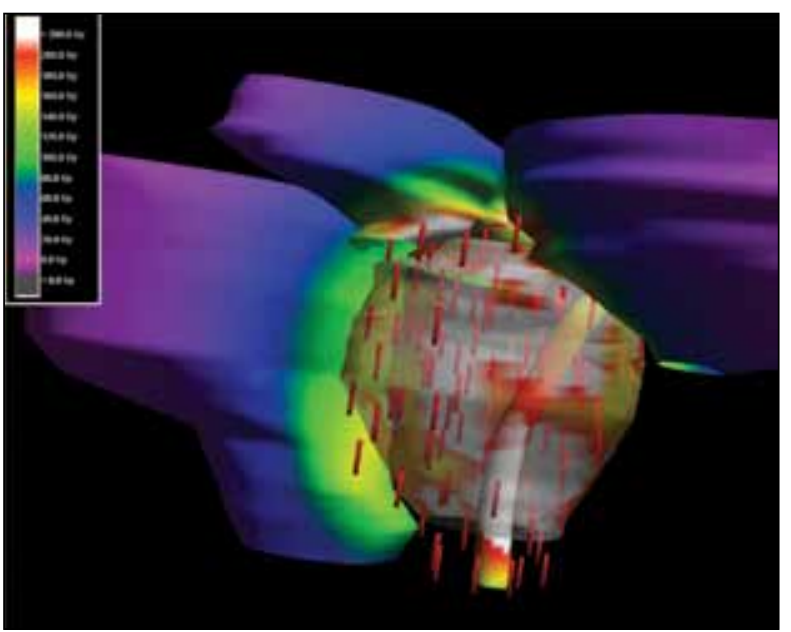

Fig. 2. Low-dose rate "colour wash" dose distribution. Colour wash with dose distribution is showing high doses of radiation directed to the prostate and base of seminal vesicles. Surrounding normal structures, bladder and rectum are receiving minimal dose. For areas coloured in blue and purple (rectum, and bladder and proximal seminal vesicles), dose is $0-60 \mathrm{~Gy}$.

resume normal daily activities in a few days. Between 70 to 150 radioactive lodine $\left(I^{125}\right)$ seeds (alternatives such as Palladium and Caesium sources are not commonly used in Canada) are implanted through 20 to 30 needles transperineally, with trans-rectal ultrasound (TRUS) guidance and occasionally fluoroscopy. Most Canadian centres use preplan techniques, developed in Seattle 20 years ago. The number of seeds implanted is determined by seed radioactivity strength, prostate size and to a smaller degree, prostate shape. As the rectal route is avoided, the risk of infection is very low. The half-life of $\mathrm{I}^{125}$ is 60 days, and therefore $50 \%$ of the radioactivity is released by 2 months, and $88 \%$ by 6 months, with $1 \%$ remaining after a year. This time course parallels the typical early side effect profile. Seed position is predetermined by a customized planning algorithm using computer modelling. A 3- to 5-mm margin beyond the anatomic prostate is included to account for potential extra-prostatic tumour extension. A postoperative computed tomography $(\mathrm{CT})$ scan of the prostate is performed to determine the actual position of the seeds, and to calculate the delivered dose distribution; this allows for the calculation of basic dose-metrics to assess the quality of the implant. This rigorous quality assurance procedure is built into all Canadian programs. Restrictions regarding radiation protection for the general public are unnecessary as the radiation exposure is very low.

In HDR, temporary catheters use single Iridium 192 source. Very high dose conformity is achieved by optimizing dwell positions of the source to generate ideal dose distribution within the prostate and limit the radiation dose to critical structures, such as rectum and urethra. Typically 14 to 18 HDR catheters are inserted into the prostate under TRUS guidance. Imaging with either CT or TRUS is performed with the catheters in place and a treatment plan generated to deliver a high dose of radiation to the target, while limiting dose to urethra, rectum and bladder (Fig. 3). The time for radiation delivery is around 10 minutes, and the whole treatment process takes about 2 hours. Although in the past patients typically received between 2 and 4 HDR fractions combined with a 4 to 5 week course of EBRT, Canadian centres have pioneered the use of single fraction HDR, 16,17 and have demonstrated equivalence between a single large fraction of 15 Gy and the previous standard of two fractions of $10 \mathrm{~Gy} .{ }^{18}$ This has become the standard fractionation in most Canadian centres, and has been widely adopted by other large international centres and by the RTOG.

HDR offers several advantages, including dose optimization, remote after-loading of the radioactive source that eliminates radiation exposure to medical personnel, and a cost-effective technique due to the use of a single reusable radioactive source. Favourable short-term toxicity and disease control ${ }^{13}$ make this procedure a preferred one in several Canadian centres. ${ }^{16,19,20}$

\section{Canadian centres offering prostate brachytherapy}

\section{British Columbia}

The British Columbia Cancer Agency (BCCA) program started in 1997, and to date has treated over 4500 patients; this is the largest program in Canada and one of the largest in the world. The current volume of 450 implants per year is shared between 16 radiation oncologists. LDR brachytherapy is available at centres in Vancouver, Victoria, Fraser Valley/Abbotsford and Kelowna. All centres use techniques based on the Seattle experience, ${ }^{2}$ combined with a planning algorithm developed in-house and consistent treatment protocols, selection criteria and rigorous quality control. ${ }^{21}$ A large provincial prospective database records baseline disease characteristics, technical (dosimetric) details, as well as follow-up PSA and side effect scores on all patients. As of 2011, HDR is offered in Kelowna.

BCCA have recently published biochemical control rates for the initial consecutive 1006 consecutive patients in BC (58\% low-risk; $42 \%$ intermediate-risk) $65 \%$ of whom received ADT for 6 months (As per 1998 BC Program policy, ADT was given to intermediate risk patients and those with prostate size $>45-50 \mathrm{cc}$.) Using Fine and Gray's competing risks analysis, the 5-year and 10-year actuarial disease-free survival (DFS) was 96.7\% (95\% Cl: 95.2-97.7\%) and 94.1\% (95\% Cl: 92.0-95.6\%) respectively (Fig. 4). ${ }^{22,23}$ Median PSA for the entire group was $0.04 \mathrm{ng} / \mathrm{mL}$, indicating that longterm cancer cure is likely in most patients. ${ }^{10,11}$ Based on program's excellent PRFS and increased technical skills of 
Keyes et al.

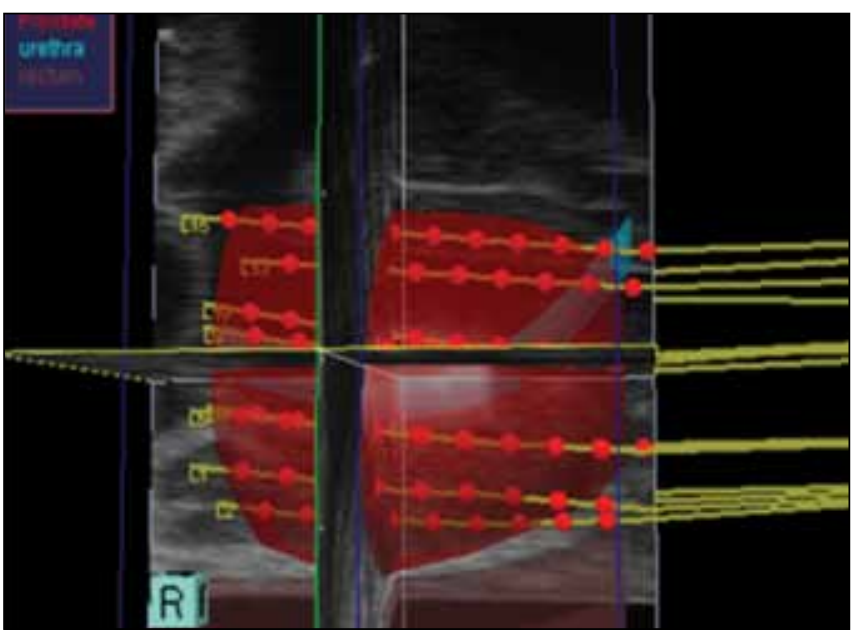

Fig. 3. High-dose rate treatment. In red, prostate contours on planning ultrasound. Yellow lines are temporary catheter positions. The red dots represent the dwell positions within the prostate, and the dwell time is reflected in the size of the dots.

the oncologist, since February 2005 the size restriction is removed and most patients with intermediate risk features $(>80 \%)$ are treated with implant alone. ${ }^{23}$

\section{Alberta}

The Cross Cancer Institute in Edmonton and the Tom Baker Cancer Centre in Calgary offer LDR brachytherapy. The Cross Cancer Institute program (also using the Seattle technique) began in 1998 and has treated over 950 patients. The current volume for 5 radiation oncologists is about 150 patients a year. The program maintains a particularly active academic interest in technical improvements in prostate brachytherapy. ${ }^{24}$ At the Tom Baker Cancer Centre, prostate brachytherapy began in 2003, using an intraoperative treatment planning approach (final placement of the seeds is planned during the procedure); this has resulted in high quality implants that appear to be comparable to those of more experienced teams. ${ }^{25}$ Both programs maintain comprehensive databases of technical and clinical outcomes. The Cross Cancer Institute recently reviewed its experience in 390 consecutive patients treated from 1999 to 2006 . With a median follow-up of 6.1 years, the PRFS was $92.9 \%{ }^{26}$ This review confirmed that treatment toxicity was comparable to other published reports.

\section{Ontario}

Prostate brachytherapy began in Ontario in 1998, and is offered at 8 centres: in Toronto at the Princess Margaret Hospital (PMH) and Sunnybrook Odette Centre, and also at the regional Cancer Centres in Hamilton, London, Ottawa, Windsor, Sudbury and Oshawa. About 400

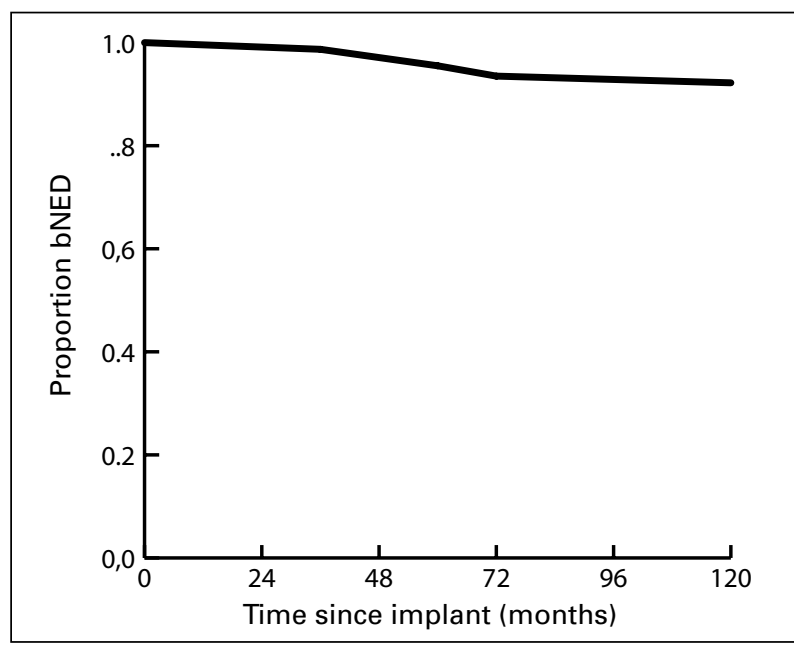

Fig. 4. British Columbia Cancer Agency 10-year low-dose rate (LDR) results. K-M bNED: consecutive 2000 LDR brachytherapy patients. There have been 82 recurrence events defined by the Phoenix (nadir $+2 \mathrm{ng} / \mathrm{mL})$ threshold. The 3, 5, 7, 10yr bNED estimates $( \pm 95 \% \mathrm{Cl})$ are $98.7 \%(0.6 \%), 95.5 \%(1.2 \%), 93.5 \%(1.6 \%)$, and $92.2 \%(2.0 \%)$ respectively (submitted for publication).

patients with low-risk disease are treated with LDR brachytherapy every year, with over 4000 patients treated to date. Funding in Ontario is more restrictive than in other provinces, and only low-risk patients are covered under the Ontario Program, although this is currently under review. At PMH, LDR brachytherapy started in 1999, with 120 patients treated per year. PMH has advocated the use of magnetic resonance imaging-CT fusion for post-implant dosimetric assessment and brachytherapy quality assurance. $\mathrm{PMH}$ has reported outcomes on 776 men (median age: 63) treated with iodine-125 PB for low- (85\%) or intermediate-risk prostate $(5 \%)$ cancer with minimum 3-year PSA follow-up. At a median PSA follow-up of 54 months, there were 27 failures, only 8 of which were local recurrences. The actuarial 7 -year PRFS was $95.2 \% .{ }^{27} \mathrm{~A}$ recently published analysis on 96 men $\leq 55$ year of age at the time of implant reports an actuarial 7 -year PRFS rate of $98.9 \% .^{28}$

\section{Quebec}

The first Canadian prostate brachytherapy program was established at I'Hôtel-Dieu de Quebec, in June 1994. So far, 1723 patients have been implanted. LDR brachytherapy is offered to low- and intermediate-risk patients. The initial report on the first 396 consecutive patients with low-risk disease, with a median follow-up of 60 months, shows a PRFS of $90.5 \% .{ }^{29}$ An updated report on the first 1110 patients treated at the CHUQ-I'Hotel-Dieu de Quebec shows 5-year PRFS of $90.5 \%$ for both low- and intermediate-risk groups. For low-risk patients, the PRFS at 5 years was $94.6 \% .^{30}$ 


\section{HDR brachytherapy in Canada}

HDR brachytherapy is currently used as a method of local dose escalation for patients with intermediate- and high-risk disease in Ontario (Toronto, London, Windsor, Oshawa), Quebec (Montreal, Quebec), New Brunswick (Moncton) and British Columbia (Kelowna), with plans to begin similar programs in St John's, Halifax, Edmonton, Calgary and Saskatoon. With a median follow-up of 7 years, the 5-year disease-free survival for men with intermediate-risk disease treated with HDR and EBRT in a Canadian multicentre study was $98 \% .{ }^{18}$ The reported 5 -year PRFS is $91 \%, 95 \%$ and $96 \%$ in single institution series from McGill University, ${ }^{17}$ Sunnybrook Odette Cancer Centre, ${ }^{18}$ and Centre hospitalier universitaire de Québec (CHUQ), ${ }^{20}$ respectively (Table 1 ).

\section{LDR side effects}

Recovery time after the procedure is short. With LDR, most men return to their usual daily activity within days. Urinary side effects are most common, with about $50 \%$ patients having immediate moderate obstructive and/or irritative symptoms. By 12 months, 90\% will have returned to baseline urinary function and by 7 years, most patients (92.5\%) will have minimal or no urinary symptoms. ${ }^{31-34}$ Patients with larger prostate volumes, worse baseline urinary function and those receiving ADT are likely to have more urinary bother after the procedure. Greater technical expertise improves the toxicity profile. ${ }^{31,35}$ Five to $10 \%$ of patients will experience urinary retention and usually require a short-term $(<1$ week) Foley catheter. In the long-term, $<3 \%$ of men will require urethral dilatation or a transurethral resection of the prostate to relieve obstructive urinary symptoms. ${ }^{31,32,36}$ Mild self-limiting rectal irritation affects $20 \%$ to $30 \%$ of patients in the first 1 to 2 years after the implant. Rectal bleeding is reported in $2 \%$ to $7 \%$ of patients. ${ }^{37}$ Rectal ulceration or recto-urethral fistulas requiring colostomy is reported in less than 1 of every 500 to 1000 patients. ${ }^{37,38}$ Biopsies of the anterior rectal wall are discouraged as even relatively minor tissue trauma can lead to a rectal fistula due to the poor vascular supply to this tissue after an implant. Similarly, laser coagulation for rectal bleeding is only undertaken when conservative measures have failed.

As with surgery, younger patients and those with better pre-treatment erectile function are more likely to preserve sexual function after brachytherapy. ${ }^{28,39-41} \mathrm{~A}$ recent British Columbia study of $>1400$ patients showed that the 8 -year potency preservation rate is $60 \%$ to $80 \%$ in men age $<60$, $55 \%$ to $60 \%$ in those between 60 and 69 years old and $20 \%$ to $30 \%$ in those over 70 years old. Loss of erectile function is most prominent within the first 3 years after the treatment, with little additional deterioration in potency rates at 5 and 8 years after brachytherapy. For the entire British Columbia

\begin{tabular}{|c|c|c|c|}
\hline Institution & $\begin{array}{c}\text { No. patients } \\
\text { with } \\
\text { published } \\
\text { outcomes }\end{array}$ & $\begin{array}{l}5 \text { year } \\
\text { PRFS }\end{array}$ & $\begin{array}{l}10 y \\
\text { PRFS }\end{array}$ \\
\hline \multicolumn{4}{|c|}{ Low and intermediate risk disease (LDR) } \\
\hline $\mathrm{BCCA}^{22,23}$ & 1006 & $96 \%$ & $93 \%$ \\
\hline Cross Cancer Institute ${ }^{26}$ & 390 & $93 \%$ & - \\
\hline $\mathrm{PMH}^{27,28}$ & 776 & $95 \%$ & - \\
\hline I'Hôtel-Dieu de Quebec ${ }^{29,30}$ & 1110 & $90 \%$ & - \\
\hline \multicolumn{4}{|c|}{ Intermediate and high risk disease (EBRT+HDR) } \\
\hline McGill University ${ }^{17}$ & 121 & $91 \%$ & - \\
\hline $\begin{array}{l}\text { Sunnybrook Odette Cancer } \\
\text { Centre }^{18}\end{array}$ & 128 & $95 \%$ & - \\
\hline $\mathrm{CHUQ}^{20}$ & 153 & $96 \%$ & - \\
\hline $\begin{array}{l}\text { Canadian Multicentre Phase II } \\
\text { study }^{18 *}\end{array}$ & 60 & $95-98 \%$ & - \\
\hline $\begin{array}{l}\text { BCCA - Phase III multicentre } \\
\text { study }^{15 * *}\end{array}$ & 78 (LDR) & $94.5 \%$ & $90 \%$ \\
\hline \multicolumn{4}{|c|}{$\begin{array}{l}\text { PRFS: Prostate-specific antigen (PSA) recurrence free survival; BCCA: British Columbia } \\
\text { Cancer Agency; PMH: Princess Margaret Hospital; CHUQ: Centre hospitalier universitaire } \\
\text { de Québec; LDR: low-dose rate brachytherapy (seeds); HDR: high-dose rate brachytherapy } \\
\text { (temporary implant); EBRT: external beam radiation therapy. } \\
\text { *Phase II multicenter trial of one vs. two fractions of HDR. **In-house report on first } 161 \\
\text { patients treated on phase II/III randomized controlled trial. Minimum follow-up } 4 \text { years. } \\
\text { Results unpublished. }\end{array}$} \\
\hline
\end{tabular}

cohort, erectile function preservation was reported in $50 \%$ of patients at 8 years, with $30 \%$ of men using phosphodiesterase- 5 inhibitors. ${ }^{40}$

PMH published a report on 1111 men with follow-up ranging to over 9 years, with $82 \%$ retaining satisfactory erectile function beyond 5 years. ${ }^{27,28,33}$ For men $\leq 55$ at the time of their prostate brachytherapy, and at a median follow-up $>5$ years, erectile function was maintained in $93 \%$, with $45 \%$ using phosphodiesterase- 5 inhibitors. ${ }^{28}$ Crook and colleagues prospectively collected quality of life outcomes in 190 patients who underwent either radical prostatectomy or brachytherapy in Ontario. Prior to making a treatment decision, patients received an hour-long joint balanced educational session by a radiation oncologist and a urologist regarding the treatment and side effects. At 5 years after the radical treatment of their choice, patients undergoing prostate brachytherapy had significantly higher overall quality of life, better urinary and sexual function and higher overall satisfaction with treatment, compared with surgery. ${ }^{33} \mathrm{We}$ recorded the LDR toxicity outcomes from other Canadian centres (Table 2).

\section{HDR side effects}

HDR brachytherapy has side-effects similar to LDR. The side-effects tend to be less intense and shorter. This is likely related to the very short radiation treatment time of 10 minutes, and the improved accuracy and precision of dose delivery compared to LDR. In patients treated with a single 
Keyes et al.

\begin{tabular}{|c|c|}
\hline Toxicity & $\begin{array}{c}\% \text { patients reported with } \\
\text { toxicity-LDR }\end{array}$ \\
\hline $\begin{array}{l}\% \text { returned to baseline urinary } \\
\text { function at } 12 \text { months }\end{array}$ & $65 \%^{31}, 73 \% \%^{32,33}$ \\
\hline $\begin{array}{l}\text { No/minimal urinary symptoms } \\
\text { with min } 7 \text { years follow up }\end{array}$ & $>90 \%{ }^{31,32,33}$ \\
\hline Urinary retention & $3 \%,{ }^{32} 5-10 \%{ }^{31,35}$ \\
\hline Late grade 2 urinary toxicity & $24 \%,{ }^{31} 10 \%,{ }^{28} 30 \%{ }^{29}$ \\
\hline Late grade $\geq 3$ urinary toxicity & $6 \%,{ }^{31} 3 \%,{ }^{28} 1.4 \%{ }^{29}$ \\
\hline TURP & $0.4 \%^{32}$ \\
\hline Late grade $\geq 2$ rectal toxicity & $9 \%,{ }^{37} 2.2 \%,{ }^{28} 0 \%{ }^{29}$ \\
\hline ED at 5 years & $7 \%,{ }^{28 *} 18 \%,{ }^{27} 24 \%,{ }^{40 * *} 50 \%{ }^{40 * * *}$ \\
\hline \multicolumn{2}{|c|}{$\begin{array}{l}\text { LDR: Low-dose rate; TURP: transurethral resection of the prostate; ED: erectile dysfunction. } \\
{ }^{*} \text { Cohort of } 96 \text { men age }<55 \text { ( } 45 \% \text { used phosphodiesterase- } 5 \text { inhibitors). **Age at implant } \\
<60 .{ }^{* * *} \text { Overall ED rate for } 1400 \text { patients } 8 \text { years follow-up ( } 30 \% \text { used phosphodiesterase- } 5 \\
\text { inhibitors). }\end{array}$} \\
\hline
\end{tabular}

15 Gy HDR and EBRT over 3 weeks, 90\% of men returned to baseline urinary function by 3 months, and less than $2 \%$ developed urinary retention requiring catheterization. ${ }^{19}$ Late rectal bleeding or proctitis is reported in less than $5 \%$. Erectile dysfunction remains the most common side-effect, with $20 \%$ developing significant erectile dysfunction that results in a high level of bother, and 30\% developing a lesser degree of erectile dysfunction responsive to PDE5 inhibitors. From older reports, we found that late urethral stricture occurred in up to $8 \%$ of patients, but more contemporary series reported stricture rates of $1 \%$ to $2 \% .^{19}$

At l'Hôtel-Dieu de Quebec, the first 44 patients treated with HDR likewise showed favourable toxicity profile. Their International Prostate Symptom Score (IPSS) returned to baseline at a median of 6 months, with $31 \%$ and $11 \%$ having acute and late urinary grade 2 toxicity (rectal bleeding). Rectal toxicity was mild with $4 \%$ having acute and $4 \%$ late rectal grade 2 toxicity. Erectile dysfunction occurs in about $27 \%$ of patients who were treated without ADT (Table 3). ${ }^{42}$

\section{Discussion}

Variations in oncological outcomes between institutions are due to differences in techniques, selection and experience. The prostate brachytherapy literature clearly documents that that individual oncologists' procedural skills and quality assurance standards are associated with long-term PSA and toxicity outcomes. ${ }^{43}$ We believe patients should be informed about expected outcomes of treatment based on the results at the institutions where they will be treated.

Canadian centres that have reported a high volume of work and have published their PSA and toxicity outcomes have excellent results, comparable to the world's best published results. ${ }^{3}$ In particular, long-term mature LDR brachytherapy results confirm the excellent cure rates of brachytherapy in low- and intermediate-risk disease in large consecutive patient cohorts treated in British Columbia, ${ }^{22}$

\begin{tabular}{lc}
\hline Table 3. HDR toxicity form Canadian centres \\
\hline Toxicity & $\begin{array}{c}\% \text { of patients reported with } \\
\text { toxicity-HDR }\end{array}$ \\
\hline Grade 2 urinary toxicity & $23 \%{ }^{16}$ \\
Acute urinary retention & $2-20 \%{ }^{18}$ \\
Late grade $>2$ rectal toxicity & $9 \%,{ }^{17} 6 \%,{ }^{18} 5 \%{ }^{16}$ \\
Late grade $>3$ urinary toxicity & $1.6 \%,{ }^{17} 1 \%,{ }^{18} 0 \%{ }^{16}$ \\
\hline HDR: high-dose rate. \\
\hline
\end{tabular}

Ontario, ${ }^{27}$ Quebec $^{30}$ and Alberta. ${ }^{26}$ While only 1 out of 10 patients treated with brachytherapy in Canada receive HDR, Canadian centres are acknowledged for innovation in HDR fractionation schedules and excellent intermediate-risk disease outcomes and toxicity. ${ }^{17,18,20}$ The typical brachytherapy toxicity profile consists of irritative and obstructive urinary symptoms, which in most patients subside by 6 to 12 months after LDR brachytherapy and likely sooner after HDR. While short-term toxicity can be pronounced for several months following the procedure, long-term toxicity is very low. Overall, serious complications or need for surgical intervention (transurethral resection of the prostate or urethral dilatation) are uncommon. ${ }^{31,33,37}$

Excellent long-term outcomes, convenience of this treatment, fast recovery after the procedure with minimal loss of working hours for patients and equivalent cost to other curative options have contributed to an increased demand for brachytherapy in Canada. It is anticipated that further brachytherapy programs will likely occur to accommodate the benefit of this dose escalation approach in high-risk patients. ${ }^{15}$

High quality assurance standards in prostate brachytherapy and institutional expertise are essential for achieving excellent long-team outcomes. Prostate brachytherapy is a highly specialized skill. As with radical prostatectomy, ${ }^{44,45}$ it is critical for brachytherapists to maintain a minimum volume of cases annually to maintain their skill-set. ${ }^{46}$ It takes about 1 year of fellowship training to practice independently with competence. Unlike with surgery, training is available in only a few centres in Canada. Training requirements are not standardized and many smaller Canadian centres are not offering this treatment. In other centres, prostate brachytherapy is still in development.

As more studies are published confirming excellent longterm outcomes, we believe the demands for brachytherapy in Canada are likely to increase. In the summer of 2011, the Chair of the Radiation Oncology Specialty Committee of the Royal College of Physicians and Surgeons of Canada has put forward a working group to develop the certification standards for a program leading to a Diploma of Special Competence in Brachytherapy. This initiative is intended to ensure high standards in training and prostate brachytherapy practice across Canada. 


\section{Conclusion}

Dose escalation with LDR or HDR brachytherapy is emerging as the most effective radiation treatment for prostate cancer, independent of risk category. Evidence suggests that use of a high dose of radiation to eradicate local disease will lead to long-term cure in many patients whom we previously believed would succumb to metastatic disease thought to be present at diagnosis. We estimate that over 13000 Canadian patients with prostate cancer had been treated with prostate brachytherapy. Canadian high volume brachytherapy centres reported long-term PSA and toxicity outcomes matching or exceeding the world's best.

We believe prostate cancer treatment is evolving and requires a multidisciplinary approach, with input from both urology and radiation oncology. Joint efforts in patient care and research collaboration will ultimately benefit our patients and further our understanding of optimal care for prostate cancer patients.

Competing interests: None declared.

This paper has been peer-reviewed.

Acknowledgements: CARO (Canadian Association of Radiation Oncology) and CBG (Canadian Brachytherapy Group) for providing some of the data presented.

\section{References}

1. Sylvester JE, Grimm PD, Wong J, et al. Fifteen-year biochemical relapse-free survival, cause-specific survival, and overall survival following $\mathrm{i}(125)$ prostate brachytherapy in clinically localized prostate cancer: Seattle experience. Int J Radiat Oncol Biol Phys 2011;81:376-81. http://dx.doi.org/10.1016/i. iirobp.2010.05.042

2. Davis BJ, Horwitz EM, Lee WR, et al. American brachytherapy society consensus guidelines for transrectal ultrasound-guided permanent prostate brachytherapy. Brachytherapy 2012;11:6-19. http://dx.doi. org/10.1016/i.brachy.2011.07.005

3. Grimm PD, Billiet I, Bostwick DG, et al. Comparative analysis of prostate-specific antigen free survival outcomes for patients with low, intermediate and high risk prostate cancer treatment by radical therapy. results from the prostate cancer results study group. BJU Int 2012;109(Supp 1):22-9. hitp://dx.doi. org/10.1111/j.1464-410X.2011.10827.x

4. Kuban DA, Tucker SL, Dong L, et al. Long-term results of the M. D. anderson randomized dose-escalation trial for prostate cancer. Int J Radiat Oncol Biol Phys 2008;70:67-74. http://dx.doi.org/10.1016/i. iirobp.2007.06.054

5. Zelefsky MJ, Yamada Y, Fuks Z, et al. Long-term results of conformal radiotherapy for prostate cancer: Impact of dose escalation on biochemical tumor control and distant metastasesfree survival outcomes. Int J Radiat Oncol Biol Phys 2008;71:1028-33. http://dx.doi.org/10.1016/i.irobp.2007.11.066

6. Dearnaley DP, Sydes MR, Graham JD, et al. Escalated-dose versus standard-dose conformal radiotherapy in prostate cancer: First results from the MRC RTO1 randomised controlled trial. Lancet Oncol 2007;8:475-87. http://dx.doi.org/10.1016/S1470-2045(07)70143-2

7. Zelefsky MJ, Yamada Y, Pei X, et al. Comparison of tumor control and toxicity outcomes of high-dose intensity-modulated radiotherapy and brachytherapy for patients with favorable risk prostate cancer. Urology 2011;77:986-90. http://dx.doi.org/10.1016/j.urology.2010.07.539
8. Deutsch I, Zelefsky MJ, Zhang Z, et al. Comparison of PSA relapse-free survival in patients treated with ultra-high-dose IMRT versus combination HDR brachytherapy and IMRT. Brachytherapy 2010;9:313-8. http://dx.doi.org/10.1016/i.brachy.2010.02.196

9. Shen X, Keith SW, Mishra MV, et al. The impact of brachytherapy on prostate CancereSpecific mortality for definitive radiation therapy of high-grade prostate cancer: A population-based analysis. Int I Radiat Oncol Biol Phys 2012;83:1154-9. http://dx.doi.org/10.1016/i.i.irobp.2011.09.055. Epub 2012 Jan 21.

10. Stock RG, Klein TJ, Cesaretti JA, et al. Prognostic significance of 5-year PSA value for predicting prostate cancer recurrence after brachytherapy alone and combined with hormonal therapy and/or external beam radiotherapy. Int J Radiat Oncol Biol Phys 2009;74:753-8. http://dx.doi.org/10.1016/i. ïrobp.2008.08.049

11. Hayden AJ, Morris JW, Keyes M, et al. The PSA value at 4-5 years after permanent prostate brachytherapy predicts for biochemical failure free survival. Radiother Oncol 2010;96:s2.

12. Zelefsky MJ, Reuter VE, Fuks Z, et al. Influence of local tumor control on distant metastases and cancer related mortality after external beam radiotherapy for prostate cancer. J Urol 2008;179:1368-73; discussion 1373 .

13. Martinez AA, Gonzalez J, Ye $\mathrm{H}$, et al. Dose escalation improves cancer-related events at 10 years for intermediate- and high-risk prostate cancer patients treated with hypofractionated high-dose-rate boost and external beam radiotherapy. Int J Radiat Oncol Biol Phys 2011;79:363-70. http://dx.doi. org/10.1016/i.i.jobp.2009.10.035

14. Lukka H, Warde P, Pickles T, et al. Controversies in prostate cancer radiotherapy: Consensus development. Can J Urol 2001;8:1314-22.

15. Morris WJ. ASCENDE-RT: Androgen suppression combined with elective nodal and dose escalated radiation therapy. http://dinicaltrials.gov/show/NCT00175396. Accessed January 30, 2013.

16. Morton GC, Loblaw DA, Sankreacha R, et al. Single-fraction high-dose-rate brachytherapy and hypofractionated external beam radiotherapy for men with intermediate-risk prostate cancer: Analysis of short- and medium-term toxicity and quality of life. Int J Radiat Oncol Biol Phys 2010;77:811-7. http://dx.doi. org/10.1016/i.i.irobp.2009.05.054

17. Cury FL, Duclos M, Aprikian A, et al. Single-fraction high-dose-rate brachytherapy and hypofractionated external beam radiation therapy in the treatment of intermediate-risk prostate cancer - long term results. Int J Radiat Oncol Biol Phys 2012;82;1417-23. http://dx.doi.org/10.1016/i.irobp.2011.05.025

18. Morton $\mathrm{G}$, Loblaw $\mathrm{A}$, Cheung $\mathrm{P}$, et al. Is single fraction $15 \mathrm{gy}$ the preferred high dose-rate brachytherapy boost dose for prostate cancer? Radiother Oncol 2011;100:463-7. http://dx.doi.org/10.1016/i. radonc.2011.08.022

19. Morton GC, Loblaw DA, Chung H, et al. Health-related quality of life after single-fraction high-dose-rate brachytherapy and hypofractionated external beam radiotherapy for prostate cancer. Int I Radiat Oncol Biol Phys 2011;80:1299-305. http://dx.doi.org/10.1016/i.ijrobp.2010.04.046

20. Bachand F, Martin AG, Beaulieu L, et al. An eight-year experience of HDR brachytherapy boost for localized prostate cancer: Biopsy and PSA outcome. Int J Radiat Oncol Biol Phys 2009;73:679-84. http://dx.doi. org/10.1016/i.i.irobp.2008.05.003

21. Keyes $M$, LaPointe V, Pickles $T$, et al. Radiation oncologists quality assurance program in $B C$ cancer agency provincial prostate brachytherapy program. Brachytherapy 2011;10:S78.

22. Morris WJ, Keyes M, Palma D, et al. Population-based study of biochemical and survival outcomes after permanent 125 I brachytherapy for low- and intermediate-risk prostate cancer. Urology 2009;73:860-5; discussion 865-7.

23. Morris WJ, Keyes M, Spadinger I, et al. Population-based 10-year oncologic outcomes after low-dose-rate brachytherapy for low-risk and intermediate-risk prostate cancer. Cancer 2012 Dec 26. http://dx.doi. org/10.1002/cncr.27911.

24. Usmani N, Sloboda R, Kamal W, et al. Can images obtained with high field strength magnetic resonance imaging reduce contouring variability of the prostate? Int I Radiat Oncol Biol Phys 2011;80:728-34. httrp://dx.doi.org/10.1016/i.ijrobp.2010.03.019. Epub 2010 Jul 12.

25. Beaulieu $L$, Evans DA, Aubin $S$, et al. Bypassing the learning curve in permanent seed implants using state-of-the-art technology. Int J Radiat Oncol Biol Phys 2007;67:71-7. http://dx.doi.org/10.1016/i. iirobp. 2006.07.019

26. Martell K, Usmani N, Sloboda R, et al. Comparing outcomes for intermediate and low-strength seeds in prostate brachytherapy. Brachytherapy 2011;10:\$92.

27. Crook J, Borg J, Evans A, et al. 10-year experience with $1-125$ prostate brachytherapy at the Princess Margaret Hospital: Results for 1,100 patients. Int J Radiat Oncol Biol Phys 201 1;80:1323-9. http:// dx.doi.org/10.1016/i.ijobp.2010.04.038. Epub 2010 Aug 1.

28. Gomez-Iturriaga Pina A, Crook J, Borg J, et al. Median 5 year follow-up of 125iodine brachytherapy as monotherapy in men aged $<0=55$ years with favorable prostate cancer. Urology 2010;75:1412-6. http://dx.doi.org/10.1016/i.urology.2009.04.101 
Keyes et al.

29. Martin AG, Roy J, Beaulieu L, et al. Permanent prostate implant using high activity seeds and inverse planning with fast simulated annealing algorithm: A 12-year Canadian experience. Int I Radiat Oncol Biol Phys 2007;67:334-41. http://dx.doi.org/10.1016/i.iprobp.2006.08.042

30. Foster $W$, Beaulieu L, Harel F, et al. The impact of $3 D$ image guided prostate brachytherapy on therapeutic ratio: The quebec university hospital experience]. Cancer Radiother 2007;11:452-60. http://dx.doi. org/10.1016/i.canrad.2007.09.144

31. Keyes $M$, Miller $S$, Moravan V, et al. Predictive factors for acute and late urinary toxicity after permanent prostate brachytherapy: Long-term outcome in 712 consecutive patients. Int I Radiat Oncol Biol Phys 2009;73:1023-32. http://dx.doi.org/10.1016/i.jirobp.2008.05.022

32. Crook J, Fleshner N, Roberts C, et al. Long-term urinary sequelae following 125 iodine prostate brachytherapy. J Urol 2008;179:141-5; discussion 146.

33. Crook JM, Gomez-Iturriaga A, Wallace $K$, et al. Comparison of health-related quality of life 5 years after SPIRIT: Surgical prostatectomy versus interstitial radiation intervention trial. J Clin Oncol 201 1;29:362-8. http://dx.doi.org/10.1200/JC0.2010.31.7305

34. Stone NN, Stock RG. Long-term urinary, sexual, and rectal morbidity in patients treated with iodine-125 prostate brachytherapy followed up for a minimum of 5 years. Urology 2007;69:338-42. http://dx.doi. org/10.1016/j.urology.2006.10.001

35. Keyes $M$, Schellenberg D, Moravan V, et al. Decline in urinary retention incidence in 805 patients after prostate brachytherapy: The effect of learning curve? Int I Radiat Oncol Biol Phys 2006;64:825-34. http://dx.doi.org/10.1016/i.i.irobp.2005.04.056

36. Keyes M, Miller S, Moravan V, et al. Urinary symptom flare in 712 (125) I prostate brachytherapy patients: Long-term follow-up. Int J Radiat Oncol Biol Phys 2009;75:649-55. http://dx.doi.org/10.1016/i. iirobp.2008.11.043. Epub $2009 \mathrm{Feb} 11$.

37. Keyes $M$, Spadinger I, Liu $M$, et al. Rectal toxicity and rectal dosimetry in low-dose-rate iodine-125 permanent prostate implants: A long-term study in 1006 patients. Brachytherapy 2012;11:199-208. http://dx.doi.org/10.1016/i.brachy.2011.05.007

38. Tran A, Wallner K, Merrick G, et al. Rectal fistulas after prostate brachytherapy. Int I Radiat Oncol Biol Phys 2005;63:150-4. http://dx.doi.org/10.1016/i.i.irobp.2005.01.021
39. Macdonald AG, Keyes M, Kruk A, et al. Predictive factors for erectile dysfunction in men with prostate cancer after brachytherapy: Is dose to the penile bulb important? Int J Radiat Oncol Biol Phys 2005;63:155-63. http://dx.doi.org/10.1016/i.irobp.2004.12.056

40. Hayden AJ, Keyes M, Moravan V, McKenzie M, Pickles T. Erectile function following II25 permanent prostate brachytherapy: 5 and 8 years results in 1411 men. Radiother Oncol 2010;96:S3.

41. Alemozaffar $M$, Regan $M M$, Cooperberg MR, et al. Prediction of erectile function following treatment for prostate cancer. JAMA 2011;306:1205-14. http://dx.doi.org/10.1001/jama.2011.1333

42. Mahmoudieh A, Tremblay C, Beaulieu L, et al. Anatomy-based inverse planning dose optimization in HDR prostate implant: A toxicity study. Radiother Oncol 2005;75:318-24. http://dx.doi.org/10.1016/i. radonc.2005.04.002

43. Stone NN, Potters L, Davis BJ, et al. Customized dose prescription for permanent prostate brachytherapy: Insights from a multicenter analysis of dosimetry outcomes. Int J Radiat Oncol Biol Phys 2007;69:1472-7. http://dx.doi.org/10.1016/i.ijrobp.2007.05.002

44. Klein EA, Bianco FJ, Serio AM, et al. Surgeon experience is strongly associated with biochemical recurrence after radical prostatectomy for all preoperative risk categories. J Urol 2008;179:2212,6; discussion 2216-7.

45. Bianco FJ Jr, Riedel ER, Begg CB, et al. Variations among high volume surgeons in the rate of complications after radical prostatectomy: Further evidence that technique matters. J Urol 2005; 173:2099-103. http:// dx.doi.org/10.1097/01.ju.0000158163.21079.66

46. Keyes M, Morris WJ, Spadinger I, et al. Radiation oncology and medical physics quality assurance in British Columbia Cancer Agency's Provincial Prostate Brachytherapy Program. Brachytherapy. In press. http://dx.doi.org/10.1016/i.brachy.2012.03.006 [corrected proof, accessed January 30, 2013]

Correspondence: Dr. Mira Keyes, Associate Professor Radiation Oncology, Department of Surgery, University of British Columbia, Head, Provincial Prostate Brachytherapy Program, BC Cancer Agency, 600 West 10th Ave., Vancouver, BC V5Z 4E6; fax: 604-877-0505; mkeyes@bccancer.bc.ca 